
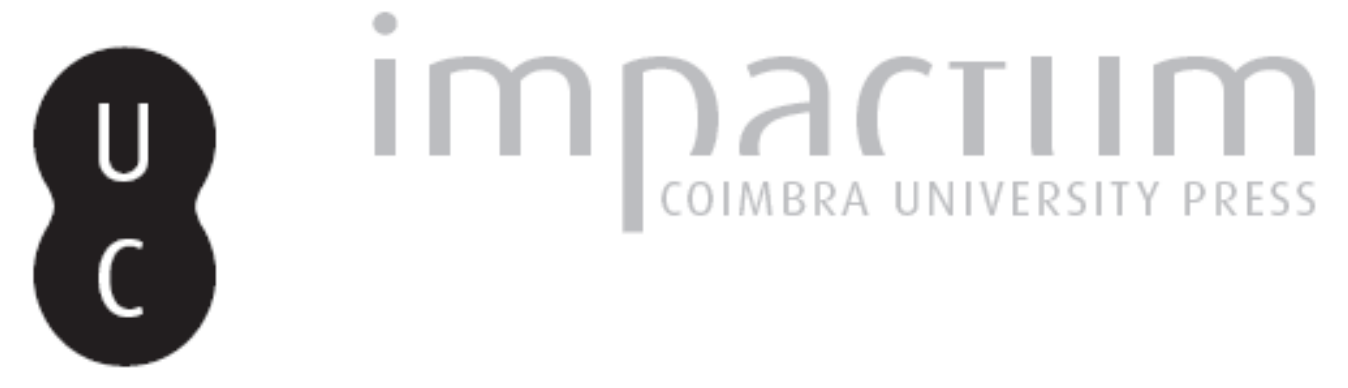

\title{
Um estudo antropológico sobre a perturbação de hiperactividade com défice de atenção na criança
}

Autor(es): $\quad$ Melo, Linda Elisabete Mendes; Quintais, Luís

Publicado por: CIAS - Centro de Investigação em Antropologia e Saúde

URL persistente:

URI:http://hdl.handle.net/10316.2/28572

DOI:

DOI:http://dx.doi.org/10.14195/2182-7982_28_1

Accessed : $\quad$ 26-Apr-2023 11:08:41

A navegação consulta e descarregamento dos títulos inseridos nas Bibliotecas Digitais UC Digitalis, UC Pombalina e UC Impactum, pressupõem a aceitação plena e sem reservas dos Termos e Condições de Uso destas Bibliotecas Digitais, disponíveis em https://digitalis.uc.pt/pt-pt/termos.

Conforme exposto nos referidos Termos e Condições de Uso, o descarregamento de títulos de acesso restrito requer uma licença válida de autorização devendo o utilizador aceder ao(s) documento(s) a partir de um endereço de IP da instituição detentora da supramencionada licença.

Ao utilizador é apenas permitido o descarregamento para uso pessoal, pelo que o emprego do(s) título(s) descarregado(s) para outro fim, designadamente comercial, carece de autorização do respetivo autor ou editor da obra.

Na medida em que todas as obras da UC Digitalis se encontram protegidas pelo Código do Direito de Autor e Direitos Conexos e demais legislação aplicável, toda a cópia, parcial ou total, deste documento, nos casos em que é legalmente admitida, deverá conter ou fazer-se acompanhar por este aviso.

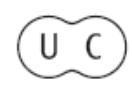




\section{Antropologia Portuguesa}

Departamento de Antropologia | Universidade de Coimbra

Volume $28 \cdot 2011$ 


\title{
Um estudo antropológico sobre a perturbação de hiperactividade com défice de atenção na criança
}

\author{
Linda Elisabete Mendes Melo', Luís Quintais² \\ ' Lageosa do Dão, Rua do Areeiro, lote 11, 3460-153 Tondela, Portugal \\ 2 Departamento de Ciências da Vida, Universidade de Coimbra, Portugal \\ linda_melo@hotmail.com
}

Resumo $\mathrm{O}$ trabalho que me proponho realizar baseia-se num estudo antropológico sobre criança hiperactiva. Ao longo de toda a pesquisa antropológica tenho como objectivo, por um lado, contribuir com um olhar mais atento ao tema criança, situar a etnografia na Antropologia médica e psiquiátrica e compreender a emergência da categoria em análise no contexto psiquiátrico. Por outro lado, no terreno, pretendo abordar o modo como é deslindado o diagnóstico hiperactivo, como a doença é entendida em contexto familiar, comunitário, escolar e como a própria criança gere o seu papel de doente, a estigmatização e o controlo exercido no seu corpo, nomeadamente, através da medicação. Neste sentido, é também útil abordar as dicotomias illness/disease, bem como estudar o modo como se delineiam as fronteiras entre o "normal" e o "patológico". Torna-se também relevante analisar, não só, o legado biológico mas sobretudo social quanto à etiologia e ideia de representação social da doença.

Palavras-chave Hiperactividade; criança; antropologia médica; psiquiatria.

\begin{abstract}
The work I propose to carry out is based on an anthropological study of the hyperactive child. Throughout the anthropological research I have as aim or objective on one side to contribute with an attentive look at the theme child, situate or place the ethnography in medical and psychiatric anthropology, and to understand the need of the categories emergency in the psychiatric context. On the other hand, I pretend to approach the way the hyperactive diagnosis is explained or found, how the illness is understood in the family, community and school context and how the child itself manages its role of ill or sick, the being put aside, and the control over its own body namely through the use of medication. It is in this way that it is also useful to approach the duality illness/disease, as well as the study of how the frontiers between "normal" and "pathological" are outlined. It is also relevant that we analyse not only the biological legacy but also the social legacy as to the aetiology and idea of the social representation of the illness.
\end{abstract}

Key words Hyperactivity; child; medical anthropology; psychiatry. 


\title{
Introdução
}

\author{
"... the child constitutes its own \\ understandings out of the meanings \\ made by all those others with whom it interacts".
}

(Toren, 1996: 94)

O trabalho que me propus realizar é o seguimento de um projecto iniciado no ano lectivo de 2006/7 no âmbito da tese de licenciatura em Antropologia. Porém, durante a realização do mestrado em Antropologia Médica ocorreu-me voltar a reflectir em muitos dos aspectos que já tinham ficado anteriormente delineados. Desta feita, conseguiu-se não só melhorar conteúdos já trabalhados como ainda introduzir novas componentes teóricas e empíricas. Este trabalho trata de um estudo muito peculiar. Aponta, em primeiro lugar, para a descrição de uma das nosologias mais frequentes na infância (Shaywitz, 1997; Blum, 1997 in Boavida et al., 1998: 21) a Perturbação de Hiperactividade com Défice de Atenção" (PHDA) ${ }^{1}$. O tema surgiu devido ao meu interesse pela Antropologia Médica, por me permitir abordar questões de saúde e de doença, por ser um tema recente, por envolver um pouco a Psiquiatria e a infância e sobretudo também por me proporcionar uma perspectiva bastante interdisciplinar. Além disso, tem-se revelado bastante aliciante trabalhar com uma ciência de "intrometidos".

\section{Metodologia}

“...the fieldworker must constantly make decisions about where to be, whom to listen to, what events to follow, and what safely to ignore and leave out."

(Sanjek, 1996: 196)

O presente trabalho insere-se no âmbito do mestrado em Antropologia Médica. Porém, é o seguimento de um projecto iniciado em 2006/7 aquando da licenciatura em Antropologia. A elaboração da primeira investigação

\footnotetext{
${ }^{1}$ Perturbação de Hiperactividade com Défice de Atenção. A psiquiatria portuguesa traduz, no manual DSM-IV-TR, «disorder» como sendo «perturbação». A autora adoptou também a palavra perturbação ao longo de todo o trabalho por uma questão de ordem e coerência.
} 
atendeu à pesquisa de livros, textos sobre o tema central que me propus a estudar. Assim como, outros documentos que de forma directa ou indirecta me pudessem auxiliar a compreender e a integrar-me com o meu objecto de estudo. Depois tornou-se pertinente que, esta investigação se fizesse acompanhar do trabalho de terreno (Augé e Colleyn, 2004: 73). O primeiro local a trabalhar foi o Hospital Pediátrico de Coimbra. Esta etapa teve início, no dia 18 de Outubro de 2006 e terminou no dia 18 de Janeiro de 2007. Com a colaboração do responsável pelas consultas de hiperactividade, Dr. José Boavida Fernandes, pude assistir a 40 consultas de hiperactividade de crianças com idades compreendidas, maioritariamente, entre 6 e 14 anos. Das quais 33 eram meninos e 7 eram meninas. Foram ainda realizadas algumas entrevistas aos familiares das crianças. Esta tarefa aconteceu, ainda no hospital. Teve início no dia 18 de Janeiro de 2007 e terminou no dia 22 de Fevereiro de 2007. O intuito desta etapa foi procurar saber junto dos pais ou outros familiares destas crianças as respostas para o porquê de recorrerem à Pediatria. Foram realizadas 20 entrevistas, nos corredores do pediátrico, úteis pela relevância do que foi e, particularmente, pelo que não foi dito por estes informadores. É importante referir que, das famílias entrevistadas, dezoito eram referentes a meninos e apenas duas a meninas. Num último momento de trabalho empírico, pareceu-me bastante relevante estudar, também, alguns pontos junto do contexto escolar. Optei por trabalhar nas escolas pertencentes ao agrupamento Inês de Castro. Talvez pela facilidade de acesso às mesmas. São elas a E.B.1 de Fala, E.B.1 de S. Martinho do Bispo, E.B.1 Póvoa, E.B.1 Espírito Santo das Toregas, E.B.1 Almas de Freire, e E.B.1 Cruz dos Morouços. Foram feitas 9 entrevistas aos professores que, tiveram início no dia 7 de Maio de 2007 e terminaram no dia 12 de Junho de 2007. Surgiu a oportunidade de entrevistar também, uma professora do ensino especial e um psicólogo, ambos pertencentes a este agrupamento de escolas Inês de Castro. Porém durante a realização da tese de Mestrado em Antropologia Médica compreendi que alguns destes aspectos poderiam ser ainda melhorados, quer a nível teórico, quer a nível empírico. Desta feita, propus-me realizar algumas entrevistas aos professores e educadores. $\mathrm{O}$ intuito destas pequenas entrevistas consistiu em questioná-los se já tiveram alunos hiperactivos e o que sabem sobre hiperactividade. Apesar de parecerem questões demasiado simplistas não o são de facto. A meu ver são questões muito importantes e fundamentais neste trabalho. Era talvez o complemento que faltava. No total foram realizadas cerca de 15 entrevistas. Por uma 
questão profissional que implicou forçosamente a minha presença na aldeia de Atalaia, pertencente à cidade de Montijo, durante os meses de Junho e Julho, a primeira parte do meu trabalho terreno foi realizado neste mesmo local. Realizaram-se 8 entrevistas a professores e educadores do infantário da escola do Afonsoeiro, ao infantário da Atalaia e à escola primária da Atalaia. Foram sempre executadas de acordo com a disponibilidade dos entrevistados durante o início do mês de Julho do presente ano, uma vez que, estando já os alunos de férias escolares tornava-se mais fácil conseguir conversar com mais calma e qualidade com alguns dos professores. Foi uma tarefa pacífica de realizar, não me senti de modo algum pressionada nem tão pouco o meu trabalho foi questionado. Senti até bastante interesse dos professores em ajudar com o que estivesse ao alcance e fosse necessário para este estudo. Foram realizadas poucas entrevistas neste local uma vez que se trata de uma aldeia em crescimento, mas ainda muito rural. Torna-se talvez mais movimentada na festa da Nossa Senhora da Atalaia que acontece uma vez por ano nos finais do mês de Agosto. Ou então, talvez, durante as visitas ao museu Agrícola e dos ex-votos. Pelo que me apercebi não há muitos professores e educadores a leccionar nesta aldeia. Certamente que alguns deles estariam também já de férias lectivas. A segunda parte deste trabalho contou essencialmente com a disponibilidade e ajuda de professores e educadores alguns de Tondela outros conhecidos, uma vez que, estes se encontravam efectivamente no período de férias lectivas mas que leccionam em Lisboa, Figueira da Foz, Coimbra e Viseu. Foram efectuadas cerca de 7 entrevistas durante os finais do mês de Julho e início do mês de Agosto do presente ano. Note-se que a parte empírica deste trabalho estava preparada para ser toda realizada no Montijo, na Atalaia, porém por várias ordens de razão não foi possível. Acredito que este acontecimento tenha sido o único grande entrave durante a realização deste trabalho uma vez que proporcionou um grande atraso na realização das entrevistas e fez com que mesmo à última hora tivesse que repensar em estratégias para solucionar a situação. Contudo, o antropólogo de terreno tem de ter esta capacidade de resolver as contrariedades, isto porque a investigação "depende de uma complexa interacção entre o problema a investigar, o investigador e os investigados" (Burgess, 1997: 6) e muitas vezes não é fácil conjugar todos. Para as entrevistas adoptei a técnica das letras, assim entrevista A diz respeito a um professor/educador, a entrevista $\mathrm{B}$ diz respeito a outro, e assim sucessivamente. Foram adoptadas as letras uma vez que já existia a numeração que diz respeito à investigação anterior. 


\section{Historiografia crítica da nosologia}

De acordo com Lopes (2004: 9) a perturbação em estudo é considerada um assunto "marginal". Possivelmente por ainda se tratar, sobretudo em Portugal, de um problema pouco conhecido, pouco ou nada debatido e escassamente estudado (Lopes, 2004: 9). Talvez por isso seja possível inferir que a hiperactividade é um assunto nitidamente difícil de aceitar, quer para os familiares, quer para os professores devido às problemáticas que gera entre ambos. Porém, esta constatação é também fruto de se estar presente no terreno e de um contacto directo com as pessoas indicadas. George Still e Alfred Tredgold (Barkley, 1998: 3) investigaram sobre esta perturbação nos finais do século XIX e inícios do século XX. Foram os primeiros autores a prestar uma atenção científica séria a este tipo de comportamento nas crianças (Barkley, 1998: 3). O pensamento deste autor, talvez, influenciado pelo contexto da época em que emergiam as ideias de Darwin, tornou-se problemático devido a uma adopção presunçosa quanto a uma predisposição biológica e, em alguns casos, hereditária dos distúrbios comportamentais (Lopes, 2004: 17). Mas na verdade o grande interesse por este tema é suscitado pelo surto de encefalite de 1917-18. Muitos dos clínicos viram-se confrontados com uma realidade pouco comum perante um sem número de crianças com sequelas muito graves do foro cognitivo e comportamental (Cantewell, 1981; Kessler, 1980 e Stewart, 1970 in Lopes, 2004: 18). A partir daqui surgiu um sem número de classificações que de modo consecutivo iam sendo substituídas por outras não menos controversas à medida que se realizavam novas investigações. "Cérebro defeituoso" (Barkley, 1998), "organic driveness" (Kahn e Cohen, 1934 in Barkley, 1998:6), "restlesness syndrome" (Childers, 1935; Levin, 1938 in Barkley, 1998: 6), lesão cerebral mínima" (Strauss et al., 1947 in Lopes, 2004: 19), são alguns dos exemplos. Nos finais da década de trinta e início da década de quarenta, tentou-se a terapia do comportamento desregrado das crianças através da medicação (Bradley, 1937; Bradley e Bowen, 1940; Molitch e Eccles, 1937 in Barkley, 1998: 7). O resultado deste modelo terapêutico teve um impacto tão forte e duradouro que constituiu uma forma privilegiada de tratamento (Keith et al., 1991; Whalen et al., 1991 in Lopes, 2004: 19), em alguns casos, possivelmente, até mesmo a única. A "síndrome hiperactiva da infância” (Burks e Chess, 1960; Ounstead, 1955 in Lopes, 2004: 23) surge e estas crianças foram então definidas como sendo "one who carries out activities a higher 
than normal rate of speed than the average child, or who is constantly in motion, or both" (Chess, 1960 in Lopes, 2004: 23). Porém, paralelamente ao comportamento evidente destes pequenos, a hiperactividade constituía cada vez mais um "mito" devido a professores e pais considerados intolerantes e a um inadequado sistema educacional (Conrad, 1975; Schrag e Divoky, 1975 in Barkley, 1998: 14). O manual DSM-II classificou uma nova categoria diagnóstica designada "Distúrbio Hipercinético da Infância", na qual os níveis de actividade destas crianças eram vistos como fundamentais na sua caracterização (Lopes, 2004: 24). Impõe-se de imediato, seguindo Quintais (2000: 33) repensar ou tomar conhecimento de uma espécie de "viragem na psiquiatria americana" que surge com o novo manual classificatório DSM-III e do qual faz parte o "Distúrbio de Défice de Atenção e Hiperactividade" (Lopes, 2004: 30). Os níveis exagerados de actividade que, até então, eram considerados a característica mais importante, dão lugar ao défice de atenção que passa a ser o aspecto caracterizador central (Lopes, 2004: 25). Uma criança pode também apresentar problemas de atenção sem hiperactividade (Fonseca, 1998: 13). O novo modelo nosológico, classificatório de doenças mentais que na sua $3^{a}$ edição (DSM-III), publicado em 1980, marcou uma profunda descontinuidade com a psiquiatria que era feita até então (Quintais, 2000:34). Com os nosologistas do DSM-III emerge uma nova perspectiva com uma matriz classificatória e uma metalinguagem psiquiátrica a ser usada universalmente não valorizando correntes científicas dinâmicas (Quintais, 2000: 36). Allen Young (1995) reforça também esta ideia de uma viragem revolucionária na psiquiatria americana com o DSMIII. A psiquiatria é apanhada «no vórtice de uma crise» (Sabshin, 1990) reemergindo a anteriormente menorizada psiquiatria biológica, alvo de um uso cada vez mais eficaz e generalizado de psicofármacos no tratamento de desordens psiquiátricas e com avanços científicos consideráveis no que respeita às neurociências (Quintais, 2000: 34). " A investigação cientifica normal é hoje, em psiquiatria, regulada por um modelo nosológico que se foi progressivamente impondo, silenciando vozes dissonantes que se the opuseram" (Quintais, 2000: 34). O manual psiquiátrico é revisto e passa a designar-se DSM-III-R (1987). Por esta altura, década de oitenta, é visível nesta fonte bibliográfica, DSM-III-R, a reemergência da hiperactividade como elemento central deste distúrbio, assim como, os problemas de atenção e impulsividade. Com o DSM-IV (1996), impôs-se uma nova forma classificatória do não mais chamado distúrbio e sim "Perturbação de Hiperactividade 
com Défice de Atenção". Seguindo o DSM-IV (1996) e a sua versão mais recente DSM-IV-TR (2002), ambos referem que a característica essencial da perturbação é um contínuo padrão de falta de atenção e/ou hiperactividade que se deve demonstrar mais grave em uns sujeitos do que em outros com um nível de desenvolvimento semelhante, uma vez que, "pessoas mais ou menos Hiperactivas, mais ou menos impulsivas, mais ou menos desatentas podem ser encontradas todos os dias sem que, por isso, se possam considerar perturbadas, doentes, desviantes ou anormais" (Fonseca, 1998: 8). Como tal, devem existir claramente evidências de um défice clinicamente significativo do funcionamento social académico ou laboral (DSM-IV-TR, 2002: 80). O manual nosológico DSM-IV-TR (2002) apresenta, tal como a sua anterior versão, três subtipos: (1) Perturbação de Hiperactividade com Défice da Atenção do Tipo Misto na qual deverão estar presentes sintomas de hiperactividade, impulsividade e défice de atenção; (2) Perturbação de Hiperactividade com Défice de Atenção Predominantemente do Tipo Hiperactivo impulsivo; (3) Perturbação de Hiperactividade com Défice de Atenção Predominantemente Desatento. Podem encontrar-se discriminadas nestes dois últimos manuais (DSM-IV e DSM-IV-TR), características específicas como cultura, idade e género importantes para uma melhor compreensão da perturbação, podendo auxiliar a avaliação diagnóstica. "The official diagnostic manual of American psychiatry (DSM-IV) now includes a brief cultural section on each category and a glossary of culture-bound syndromes written by ethnopsychiatrists; following recent anthropological and historical interest in Western psychiatry" (Littlewood, 1996: 200).

\section{Antropologia médica e Psiquiatria}

A biomedicina é o produto da dialéctica entre natureza e cultura e esta é uma das primeiras problemáticas da antropologia médica (Hahn e Kleinman, 1983: 321). Deste modo, estar doente não é apenas um estado biológico, constitui conjuntamente um estado social. Neste sentido, Duarte (2002) faz uma chamada de atenção para a forma como os indivíduos expõem os seus sintomas, como falam dos seus problemas de saúde, quando e onde procuram ajuda. Conforme refere Duarte (2002) não é que a doença não possua uma base biológica ou que o significado dos sintomas seja independente da condição física, é urgente esclarecer que questionar sintomas, releva-se mais informativo para o antropólogo, sobre a condição humana do que, propria- 
mente, apenas a doença enquanto disease, enquanto disfunção física e biológica do organismo. Contudo, "quando nos referimos às componentes sociais da doença não queremos afirmar que a etiologia da doença é exclusivamente social, mas que a sociedade tem um duplo papel no enquadramento das situações patológicas, isto é por um lado efectivamente gera condições para o desencadear da doença e por outro lado oferece igualmente um conjunto de normas de adaptação e aceitação dessa mesma doença" (Duarte, 2002: 48). Esta ideia remete-nos, de imediato, para uma construção social da doença que é, também ela, reforçada por Swaan (1990: 15). Quando se refere aos problemas mentais, este autor acrescenta que, "such mental problems must be articulated, told and "made" by the patient and his therapist. In that sense, they represent social constructions." Conforme esclarece Quartilho (2001) a doença reflecte uma dialéctica entre o corpo e a sociedade. Por um lado, é no corpo que os sintomas são muitas vezes procurados quer pelo paciente, que tenta compreender o que se passa com o seu corpo, quer pelo próprio médico que tenta rapidamente encontrar a origem do problema da doença. Os médicos de certa forma, são treinados para "fazer qualquer coisa" uma vez que o seu trabalho visa contribuir para o bem-estar dos doentes e tendem a encontrar doenças, por não quererem perdê-las (Quartilho, 2001: 162). "Les médicins se désintéressent d'un concept ...ce qui les intéresse, c'est diagnostiquer et de guérir. Guérir c'est en príncipe ramener à la norme une fonction ou un organisme qui s'en son ecartés " (Canguilhem, 1994: 75). Muitas vezes não por sua culpa, mas devido a um sistema de trabalho que visa ser sistemático, rápido e eficiente apresentando rapidamente um produto final. Ainda de acordo com esta linha de pensamento, os médicos têm tendência para ignorar ou subestimar o papel dos factores "psicossociais" ou ainda questões relacionadas com "cultura", "contexto de vida", ou mesmo os "percursos individuais" que adquirem um estatuto marginal quase exótico no discurso institucional da medicina (Quartilho, 2001: 163). Como descreve Quartilho (2001) os sintomas do corpo podem constituir metáforas de mal-estar individual, social e político. Por essa razão não podem ser reduzidos a um vocabulário estritamente biológico correndo o risco de ser perdido o verdadeiro significado dos sintomas ou da experiência subjectiva. Será que é pelo facto de um indivíduo estar doente que é considerado anormal. Se assim for, estamos perante um equívoco, uma vez que, "une santé parfaite continuelle est un fait anormal" (Canguilhem, 1994: 86). Swaan (1990: 1), reforça esta ideia "a body must be rested, cle- 
aned, groomed, and every day; it must be fed properly and decorously at the correct time and it must be made to walk the right tracks and talk the right things". Em muitos casos, é simplesmente pelo facto de um individuo procurar cuidados de saúde/doença que se vê notoriamente confrontado com uma tendência para ser etiquetado ou, simplificando, como pertencente a uma determinada entidade diagnóstica. É claramente difícil manter aquilo que se considera normalidade, de acordo com a linha de pensamento de Swaan (1990), mesmo porque algumas pessoas podem fazer de outras doentes, contaminando, culpabilizando, humilhando, chantageando, excluindo e promovendo alguns dos desvios, que mais tarde vêm a reclamar. Muitas das crianças acompanhadas enquadram-se nesta situação. A estigmatização é também um contributo no uso dos conceitos "normal" e "patológico". É essencial compreender o valor do termo controlo neste contexto. O controlo é exercido através da aplicação de técnicas de intervenção e autoridade social que vão muitas vezes além do processo de cura usualmente às relações sociais (Kleinman, 1991: 124). Foucault (1977) questionou-se sobre a "disciplina" e sobre o modo de "fabricar" corpos submissos e dóceis. Torna-se pertinente sobretudo pelo facto de estas situações poderem ser encontradas nos colégios, nas escolas primárias, no contexto hospitalar e ainda no contexto militar (Foucault, 1977: 125). Exige-se, diariamente, disciplina, postura e regras às crianças, quer em casa quer na escola. Um dos aspectos mais desassossegantes, quanto às doenças mentais, prende-se com o facto de estas não encontrarem aquilo a que Quintais chama de "suporte traumático" e que se inscreve no corpo de um modo inquestionável (Quintais, 2002: 372). Jan Goldstein (1987), aborda o tema da hiperactividade e a respeito refere dois pontos dignos de nota. Em primeiro lugar, faz pensar como pode ser vantajoso para os vários profissionais fazerem da perturbação de hiperactividade uma anomalia biológica, passível e obediente a um tratamento com medicação "the biological construction points to the least expensive solution, and away from such costly and time-consuming alternatives as psychoterapy or family therapy" (Goldstein, 1987: 404). Em segundo lugar, demonstra como a perturbação de hiperactividade emergiu no seio de uma sociedade capitalista que toma como garantido que a capacidade em estar atento é uma característica essencial para um desenvolvimento económico e social. "It is the disease of a culture that routinely demands attention of its children, that sees performance in school as laying the foundation of a child's future, but that simultaneously undermines the 
attention span through the constant, fast-paced, sensory overload emanating from its media" (Goldstein, 1987: 405). Por outro lado, os manuais de doenças psiquiátricas (DSM) reflectem "...the growing tendency in our society to medicalize problems that are not medical, to find psychopatology where there is only pathos, and to understand phenomena by merely giving them a label and a code number" (Make Us Crazy, 1997 in Horgan, 1999: 80). O que acontece é que, a sociedade exige das crianças que estejam atentas e que se comportem devidamente. Por outro lado, proporciona todo o tipo de estímulos distractivos e quebra com a criança um conjunto de hábitos primários. "Com o crescimento, estas imposições sociais aumentam: não pode fazer barulho, não pode escangalhar os bonecos, não pode tirar a goludice do prato em que se encontra; tem de pedir licença aos pais para se levantar da mesa, dar os bons dias e as boas noites, estar quieto à mesa, etc., etc., etc." (Fontes, 1948: 425). Em muitos casos, a criança "reage pela negação, pela oposição, ao que se lhe manda fazer, o que leva ao estado mais ou menos intenso, mais ou menos permanente de rebeldia; ou então transfere a sua situação afectiva para outra um tanto afastada do conflito que originou a sua reacção" (Fontes, 1948: 425). Compreende-se, tal como também refere Fukuyama (2002: 86) que, existem sem dúvida casos de pessoas cuja hiperactividade ou capacidade de concentração são de tal modo evidentes que lhe deve ser reconhecida uma situação patológica. Aliás a questão que aqui se impõe não é a veracidade de uma criança sofrer ou não da perturbação. Partindo da ideia de que, a medicina pode ser vista como um sistema cultural, um sistema de significados simbólicos ancorados em significados particulares de instituições e padrões de interacções interpessoais (Kleinman, 1980: 24) pretende-se questionar a prática médica, sistemas de doença/cura, bem como compreender a experiência pessoal de cada doente. "Anthropologists have so readily assumed that the study of careseeking choices provides an obvious entree into describing a medical system...guided by their personal beliefs, are so often the primary focus of investigation and analyses" (Good, 1994: 47).

\section{Contexto I-Hospital}

Foram observadas 40 consultas de Hiperactividade das quais 33 eram meninos e 7 eram meninas. Foi com o continuar das observações que se tornou possível compreender que se tratava de um mesmo problema e de uma 
mesma descrição, ou então muito parecida, em famílias diferentes. Quando os familiares das crianças se dirigiam a estas consultas de hiperactividade levavam já sinalizados alguns traços gerais da perturbação. Em alguns casos, este problema tinha sido percepcionado desde cedo, em casa. Em outros casos, foi apenas com a entrada na escola, por volta dos seis anos de idade que se tornou um verdadeiro problema. Ou ainda, a pressão das duas situações obrigou, indubitavelmente, a que os familiares solicitassem um apoio médico. É certo que, na maior parte dos casos, os familiares antes de irem às consultas não sabiam exactamente o que se passava com as suas crianças. Apercebiam-se, apenas, dos comportamentos que, vivenciavam em casa ou em locais públicos e que frequentemente os incomodava. Todas as crianças acompanhadas foram descritas, pelos pais, como sendo "hiperactivas", "desatentas", "perturbadoras", "irresponsáveis", "trapalhonas", "teimosas" ou mesmo "desorganizadas". Muito comum foi ouvir também que, "falham por não ouvirem com atenção, perdem os amigos por serem crianças bastante "conflituosas" ou "socialmente desajeitadas". Segundo o Dr. Boavida Fernandes, "tão depressa fazem amigos como os perdem. Não os conseguem manter com brincadeiras ou conversas, pois é precisamente neste campo que são desajeitadas" (O.C.7) ${ }^{2}$. Expressões do género, "envergonha-nos em todo o lado", "parece que está sempre no mundo da lua", "parece o diabo", mas mais preocupante é quando se ouve um familiar dizer, "que mal fiz para merecer uma coisa assim"ou então "ele faz-me pensar onde é que eu errei" (E.F.9)3. . Estas expressões permitemnos compreender o quanto os familiares se culpabilizam pelo problema dos filhos e também o quanto sofrem. A vontade de verem o problema dos filhos resolvido é imensa. No entanto, este é um processo que exige muito tempo, paciência e dedicação. Geralmente a saturação dos familiares leva à constante culpabilização. As afirmações dos vários familiares durante as consultas são tão interessantes quanto assustadoras. Queixam-se sobretudo de que a criança "não pára, está impossível", "se eu não o medicasse queria ver, o Dr. tem de experimentar levá-lo lá para sua casa" (O.C.1). Por outro lado, referem também as queixas provenientes da escola. "A professora já não o aguentava" (O.C.1), "a professora ao terceiro dia de aulas já não o aguentava" (O.C.2). A cada consulta que passava podia registar no diário de campo uma nova queixa que os pais apresentavam, em jeito de desabafo com o médico,

\footnotetext{
${ }^{2}$ Observação da consulta número sete.

${ }^{3}$ Entrevista à família número nove.
} 
quanto aos professores e à falta de entendimento com as crianças. Estes pais geralmente comentavam que "os professores não estão minimamente sensibilizados para trabalhar com estas crianças” (O.C.9). Sobre isto, é essencial referenciar a opinião do Dr. Boavida Fernandes que, tantas vezes explicou a estes familiares que "a hiperactividade não é um problema disciplinar mas sim comportamental, as crianças não têm culpa disso, é um problema que elas não controlam" (O.C.40). Talvez, seja relevante acrescentar que, em apenas um caso, dos quarenta observados, uma professora acompanhou a criança (sua aluna) com PHDA ao hospital juntamente com os pais. Naquele gabinete médico, entravam juntamente com as crianças com PHDA, todo um conjunto de diferentes tipos de problemas familiares, sociais e económicos. A mãe do menino da consulta número vinte e nove apoiava o filho em vários desportos radicais, demonstrou-se sempre uma mãe muito atenta e interessada, questionava insistentemente o pediatra de modo a esclarecer as suas dúvidas e a procurar o melhor para este adolescente. No caso da observação da consulta número doze os pais deste menino tinham sérios problemas com álcool. Argumentavam não ter "disponibilidade" para levar a criança às consultas de terapia da fala. As queixas, sobre esta criança, por parte da escola eram muitas e relacionadas com mau comportamento e agressividade aos colegas e professores. Houve um momento em que o médico questionou esta mãe sobre o comportamento do filho em casa. A resposta dela foi "o nosso dia-adia é passado no monte a guardar ovelhas, lá ele anda à vontade” (O.C.12). Durante a observação da consulta número catorze, uma mãe, com problemas depressivos, que passava por uma situação de divórcio, descreveu o filho da pior maneira que conseguiu. Chegou inclusivamente a pedir consultas de pedopsiquiatria, por reclamar que o filho não melhorava e que, com ou sem medicação era igual, "continua impossivel de aturar" (O.C.14). Durante a observação da consulta número quatro, a criança em causa, interrompia várias vezes o médico, questionando o porquê de lhe fazerem tantas perguntas e tantos testes, chegou mesmo a perguntar se já não chegava. Fez apenas pensar sobre como estas crianças devem chegar a um ponto de saturação. São de facto, muitas consultas, muitos testes de avaliação que, obviamente são essenciais no estudo da perturbação, mas que por outro lado, contribuem também para um desgaste psicológico destas crianças. Muitas delas não compreendiam o que iam fazer àquelas consultas, primeiro porque algumas eram muito pequenas e ainda não estava ao seu alcance compreender. Por outro lado, compreender não poderia ser possível, uma vez que possivelmente ninguém lhes explicava. 
Torna-se também difícil perceber se é porque sofrem da PHDA que são estigmatizadas, ou se por outro lado, é porque são fortemente estigmatizadas que elas "falham constantemente" e têm essa tendência para "parecer o diabo" tal como os familiares as descrevem. De qualquer forma, estes familiares vivem, indubitavelmente, situações particularmente difíceis junto das suas crianças. $\mathrm{O}$ seguinte caso de uma mãe que durante a entrevista referiu a seguinte situação: - "Olhe, tenho uma boa história para lhe contar, um dia fiz a festa de anos para o meu filho e convidei os 19 colegas da turma para irem, sabe quantos lá apareceram? Apenas dois meninos... Já pode ver! Os pais não deixavam os miúdos ir à festa do meu filho. Mal me falavam, eu fiquei de rastos e o meu filho então... Sabe é que isto acontecia repetidamente...os miúdos não brincavam com ele por causa do problema dele".

\section{Contexto II- Famílias}

Uma vez que se dirigem a estas consultas dezenas de familiares por dia, tornou-se mais fácil encontrar, neste local, pais disponíveis para uma pequena entrevista. Por outro lado, o difícil foi fazer com que mães e pais falassem abertamente deste assunto. Houve familiares que ficaram emocionados, não queriam falar ou então falavam muito pouco. Até certo ponto, tornou-se mais interessante reflectir sobre estes últimos familiares. Aqueles que nada disseram foram, sobretudo, os que mais fizeram pensar e repensar no porquê dessa atitude. Talvez a ideia de terem que descrever e reviver momentos particularmente complicados não lhes agradasse ou causasse bastante desconforto. Por um lado, foi em casa e através dos amigos ou outros familiares que se aperceberam do comportamento dos filhos. "Desde bebé que me apercebi que o meu filho era uma criança muito irrequieta. Não se sentava a ver televisão, por exemplo. E teve sempre tendência para piorar, ao longo do tempo tornou-se muito desatento, mexia-se (agitado) bastante em relação aos primos. O meu filho era uma criança que não media perigos (E.F.2). "Desde muito pequena a minha filha não sossegava, em casa dizíamos-lhe que estivesse sossegada e mesmo assim ela teimava em continuar a fazer 'coisas' [actividades, jogos etc], percebemos que não era uma situação normal" (E.F.4). "Desde bebé que o meu filho nunca conseguia dormir devidamente. Nunca estava quieto, andava sempre aos saltos e movia-se que era uma coisa fora do normal ".Por outro lado, a pressão dos professores que frequentemente faziam uma nova queixa ou enviavam um 
recado sobre o "mau comportamento" das crianças foi também um motivo para que os familiares tomassem uma atitude. "Foi na primeira classe que se revelou bastante perturbador. Em contexto de sala de aula virava as cadeiras ao contrário, teimava em não querer estudar, apesar de ser um bom aluno, os recados eram semanais" (E.F.1). "Tudo começou na pré-primária, as professoras diziam-me que ele não fazia amigos como as outras crianças porque ninguém queria brincar com ele. Era frequente as pessoas dizerem: vê o teu menino. Olha que ele não é igual aos outros, alguma coisa se passa com ele. Olha que ele não é normal, ele é diferente. Isto porque uma vez ele riscou o carro a uma professora e partiu um lavatório na escola" (E.F.12). Porém, estas crianças criam um desgaste aos familiares que em muitas situações talvez sejam estes últimos a necessitar de apoio. "É muito dificil lidar com os meus filhos porque ainda hoje não estou consciente deste problema" (E.F.6). "É muito dificil fazer com que ele se concentre, faça as "coisas" dele como deve ser. Há dias em que chora ele e choro eu. Tenho lido bastante para me informar do problema do meu filho e para o poder ajudar muito mais" (E.F.13). "Embora o meu filho já tenha um comportamento um pouco melhor, cansa bastante em termos psicológicos” (E.F.7). "Eu não podia ir às compras e levá-lo, que ele fazia espectáculos em todo o lado. Eu por vezes até me evitava de sair" (E.F.12). Por outro lado, estes familiares atribuíram também uma parte da responsabilidade aos professores. "Alguns professores não têm conhecimento de como lidar com estas crianças. Chegaram a mandar o meu filho para a rua, na escola, porque ele se portava mal. Não entendiam que só faziam o que ele queria, não ter aulas", (E.F.1). "Logo no primeiro ano, nos primeiros dias de aulas a professora chamava-me constantemente à escola, dizia que o meu filho a provocava e que quando teimava não fazia nada. De facto, o meu filho é teimoso, mas eu conheço-o e acho que faz parte da sua personalidade. Além disso sempre foi acompanhado por pediatras e nunca foi diagnosticado nenhum problema. Um dia fui chamada à escola pela professora de apoio às quatro da tarde. Quando lá cheguei a professora de braços levantados, gritou e disse, à frente de toda a turma: o seu filho está incontrolável, está possesso e diabólico! Ao que eu respondi que não lhe admitia tais observações pois estava a construir uma barreira entre o meu filho e os amigos e poderia tornar-se num motivo para nenhum deles brincar com o meu filho. Nunca a tratei mal, embora tivesse vontade. Olhe, desculpe o termo, mas ela às vezes parecia uma cabra aos berros, eu tinha medo que ela castigasse o meu 
filho. Se ela o fizesse eu nunca o iria saber porque ele é muito reservado. As poucas coisas que dizia sobre a professora era " mamã a professora não gosta de mim, ela odeia-me." Claro que, estando eu com a cabeça cheia de recados da escola, quer dados pela professora, quer pelos outros pais e amigos, castiguei-o muitas vezes. Por exemplo, eu ia à escola buscá-lo, chegava lá e um amigo dele vinha-me dizer, olhe a professora quer falar consigo. $O$ engraçado é que os amigos da $4^{a}$ classe, que dividiam a sala de aula, diziam-me que ele se portava bem e fazia os trabalhos todos. Em cada ano como era uma professora diferente o meu filho destabilizava. No segundo ano, foi então outra professora, que me dizia que, nas aulas o meu filho partia a borracha entre outras coisas, mas não dizia que ele era mal portado. Eu perguntava-lhe constantemente como ele se portava e um dia ela até me disse, está a ser feliz, coisa que nunca foi! Passado uns tempos, como lhe devem ter dado a conhecer a situação do ano anterior, chamoume à escola e diz-me ela: "ou tratam desta criança ou vou por outros meios", isto no meio de uma reunião. Olhe que eu até lhe pedi por favor para conversar com o meu filho para o acalmar e diz-me ela novamente: "oh minha senhora você não sabe o filho que tem"! Por eu saber o filho que tenho é que lhe estou a pedir. Com os amigos e colegas passava-se o mesmo, apesar de eu ter a porta de casa "sempre aberta" para os amigos dele, ninguém lá vai brincar com ele, eu não entendo o que se passa. Ah! Sabe o que me diziam os auxiliares escolares? O seu filho é um mimado! No terceiro ano, teve outra professora, contei-lhe todos os problemas que se tinham passado nos anos anteriores. Como era professora de ensino especial era muito mais compreensiva e meu filho respeitava-a muito. Ela teve outra atitude! Um dia desses, numa reunião, disse a todos os pais que não havia na turma dela nenhuma criança dificil e que não havia nenhum problema, ao contrário das anteriores. Entretanto, foi necessário que, o meu filho mudasse de escola. Houve uma altura que, uma contínua me disse "ah, estávamos a espera que o seu filho fosse do piorio, pensávamos que em sua casa não havia regras ". Veja lá como está a imagem do meu filho, descrevem-no como se ele fosse um monstro! Um dia consegui uma consulta com o Dr. Boavida e foi quando ele fez os primeiros testes com a psicóloga, foi-lhe então diagnosticada a hiperactividade. Começou a tomar $20 \mathrm{mg}$ de Ritalin LA em 2006. Finalmente depois da consulta tudo melhorou quer com os professores quer com o meu filho" (E.F.3). 


\section{Contexto III- Escolas}

É importante começar por referir, de acordo com os professores, que a criança com $P H D A$, neste momento, não faz parte do quadro de crianças com necessidades educativas especiais. Isto significa que, anteriormente, estas crianças possuíam outro tipo de atenção ou apoio a nível escolar, que por si só, era um direito. Implicando um determinado número de horas disponibilizadas pelos professores de educação especial a estas crianças. Presentemente, o que se verifica é que, com esta nova legislação de avaliação e também de acordo com o que me foi dito pelos professores, só recebe um apoio especial, a criança que sofrer de problemas graves de conduta. Isto devido a um documento a $\mathrm{CIF}^{4}$, que indica a que tipo de situações se atribuem as necessidades educativas especiais. "Consideram-se alunos com necessidades educativas especiais de carácter prolongado, aqueles que, experienciam graves dificuldades no processo de aprendizagem e participação no contexto escolar, familiar, comunitário decorrentes da interacção entre factores ambientais (físicos, sociais e atitudinais) e limitações de grau acentuado ao nível do seu funcionamento num ou mais dos seguintes domínios: motor; cognitivo; comunicação; linguagem e fala; emocional e personalidade", Dois aspectos interessantes sobre este documento, a CIF, e que em todas as entrevistas foram reforçados pelos professores são referentes, em primeiro lugar, à falta de uma orientação aos professores, no sentido de, estes compreenderem como funciona esta nova legislação, o documento é pouco claro nesse sentido. No entanto e mais pertinente, ainda, é que apesar disso, os professores ficam incumbidos de classificar a gravidade do problema de cada criança, para fazer cumprir a legislação do documento. Uma vez que, a criança com PHDA deixou de ter direito a horas suplementares de educação especial resta-lhes apenas a disponibilidade que cada professor pode despender, de acordo, com a situação das restantes crianças da turma. Segundo os professores entrevistados, é muito difícil apoiar todas as crianças visto que, "hoje em dia as crianças problemáticas constituem a regra e não a excepção” (E.P.4) ${ }^{6}$. Cada professor adopta o seu método e o seu tipo de estratégias. De acordo com o que me foi dito, há professores que adoptam "um tempo diário de trabalho autónomo" que

\footnotetext{
${ }^{4}$ Sistema de Classificação Internacional de Funcionalidade, Incapacidade e Saúde.

${ }^{5}$ Retirado de http://www.dgidc.min-edu.pt/especial/PDF/avaliacaoNEE.pdf

${ }^{6}$ Entrevista ao professor número seis.
} 
consiste em cada criança trabalhar os assuntos a que têm mais dificuldades, com o professor, com os colegas ou sozinha. É preparado material de apoio para trabalhar individualmente cada criança com PHDA, que sozinha não consiga acompanhar o ritmo dos colegas. Os professores referiram dar sempre explicações adicionais, alguns deles proporcionam aulas de apoio três vezes por semana, dentro da sala de aula. Facultam também testes com mais tempo de duração e faseados, testes com escolha múltipla, questões directas, fichas de avaliação adaptadas ao grau de desenvolvimento de cada uma das crianças com PHDA. De acordo com a professora de educação especial entrevistada o que acontece é que "estas crianças passaram a ter condições especiais de avaliação” (E.P.E.E.8)7. A entrevista ao psicólogo do agrupamento destas escolas foi favorável para o conhecimento da aplicação de técnicas a nível comportamental que visam essencialmente controlar o comportamento das crianças. Quando a intervenção comportamental não é suficiente ou quando se trata de casos mais graves, estas crianças são encaminhadas para o Hospital Pediátrico de Coimbra para uma intervenção a nível da medicamentação. No entanto, a medicação acarreta uma enorme controvérsia. Em muitos casos a criança está medicada mas não tem nenhum outro tipo de apoio, "parte-se do princípio que uma criança medicada é uma criança tratada” (E.P.1). Durante esta mesma entrevista, a professora entrevistada, apesar de compreender que, em muitos casos a medicação é bastante útil e melhora o comportamento destes meninos e meninas, referiu ainda o seguinte, "parece-me que estamos a construir a geração ritalin" (E.P.1). A ideia para a qual esta profissional me chamou claramente à atenção assenta, essencialmente, no uso e no abuso dos fármacos prescritos para controlar esta perturbação. Todos os professores entrevistados culpabilizaram os profissionais de saúde que, seguem cada uma destas crianças, na medida em que não colaboram com os professores ajudando com o envio de documentação clara, sobre o que se passa com cada um destes meninos e meninas que os médicos reclamam sofrerem da PHDA. Gostariam essencialmente de receber o "feedback" das informações que enviam para o hospital. Isto é, fornecem um conjunto de informações ao hospital sobre a criança em causa e os profissionais de saúde enviam um documento, tal como também pude observar, que apenas diz o nome da perturbação de que a criança sofre e em alguns casos o nome da medicação prescrita. Os professores entrevistados

\footnotetext{
${ }^{7}$ Entrevista a uma professora de educação especial número oito.
} 
opõem-se a este modo de agir. Por isso mesmo demonstraram-se interessados, pelo menos durante o momento em que permaneci no terreno, em ter conhecimento sobre as características em que os médicos se baseiam para sustentar o diagnóstico de PHDA. Lamentam não trabalharem devidamente com estas crianças por não saberem em que batalhar, queixam-se de fazer um "trabalho às escuras" (E.P.5).

\section{O que sabem os professores sobre hiperactividade}

Tal como foi referido na metodologia, a componente prática do presente trabalho foi elaborada em locais diferentes. Na totalidade permiti-me realizar 15 entrevistas, 8 das quais foram efectuadas na aldeia da Atalaia e 7 foram realizadas a professores e educadores de variados locais consoante a disponibilidade dos mesmos. Tenho agora o momento oportuno para justificar o porquê de insistir com as escolas e com os professores. Do meu ponto de vista, as crianças de hoje passam cada vez mais tempo nas escolas, espaços de lazer, nas salas de informática ou em qualquer outro espaço público. E por conseguinte, cada vez mais distantes do domínio privado da educação familiar. Por esta mesma razão batalhei nas entrevistas com os professores pois cada vez mais, são eles quem melhor conhece cada criança. Por isso, é com eles que estão a grande parte das respostas.

Entrevista B: Educadora há 25 anos, Atalaia (Montijo)

Entrevistadora: Já teve crianças hiperactivas?

Educadora B: "Não, felizmente".

Entrevistadora: O que sabe sobre hiperactividade?

Educadora B: " sei que se fala de hiperactividade há cerca de 10 anos. Já tive meninos com muita dificuldade de concentração e instáveis, mas não sei se eram hiperactivos. É preciso muito cuidado na forma de rotular as crianças. Sei que a falta de regras no ambiente familiar se reflecte no ambiente escolar".

Entrevista I: Educadora de infância há 2 anos em Lisboa.

Entrevistadora: Já teve crianças hiperactivas?

Educadora I: "Com certeza absoluta não".

Entrevistadora: O que sabe sobre hiperactividade?

Educadora I: "É uma doença em que os principais sintomas são a agitação, a falta de concentração. Não tem nada a ver com a falta de educação. 
Quem tem uma grande experiência tem capacidade para distinguir as duas situações. Falta de educação têm todos hoje em dia, mas os hiperactivos têm características mais específicas. Os pais têm certas dificuldades em reconhecer que os filhos possam ter este distúrbio ligado à hiperactividade. Parte dos professores alertam e nem assim. Por iniciativa própria os pais não procuram pessoas ligadas à área de saúde. E a falta de educação dos miúdos acaba por ser uma desculpa”.

Entrevista J: Educadora de infância há 2 anos em Lisboa.

Entrevistadora: Já teve crianças hiperactivas?

Educadora J: "Não".

Entrevistadora: O que sabe sobre hiperactividade?

Educadora J: A hiperactividade é um desvio do comportamento das crianças com características que se confundem com mau comportamento. É um excesso de actividade. Estas crianças não conseguem estar paradas. Cada vez mais se fala de hiperactividade nas crianças. E também temos tendência para dizer que a criança irrequieta é hiperactiva".

Entrevista N: Educadora de infância há 1 ano, Figueira da foz. Actualmente em estágio profissional no Jardim-Escola João de Deus.

Entrevistadora: Já teve crianças hiperactivas?

Educadora N: "Não trabalhei com crianças hiperactivas mas conheço um caso no Jardim Escoa João de Deus na Figueira da Foz, onde estou a estagiar. Trata-se de um menino de 5 anos, portanto em idade pré-escolar, que foi diagnosticado como hiperactivo e já toma medicação, basicamente estimulantes. É um miúdo muito irrequieto, com um olhar agitado, muito curioso. Haverá alguns problemas conjugais com os pais da criança mas não se sabe até que ponto isso pode influenciar o comportamento da criança. No método de ensino João de Deus, a criança começa a aprender as ferramentas básicas do conhecimento - ler, escrever, operações matemáticas - com 5 anos. É plausível que esta criança tenha sido precocemente diagnosticada e medicada, isto é, antes da idade escolar oficial, por ter sido integrada no sistema João de Deus.

Entrevistadora: O que sabe sobre hiperactividade?

Educadora N: "Hiperactividade é um desvio comportamental de base biológica. O contexto social influência o estado da criança e potencia a predisposição genética. A hiperactividade não pode ser diagnosticada a crianças muito pequenas nem se mantém ao longo da idade adulta; é um desvio 
particular que se manifesta na infância; no entanto, certos sinais de comportamento hiperactivo em crianças podem prolongar-se pela idade adulta: têm comportamentos repetitivos, tiques e sinais que denotam uma certa dificuldade em se concentrar. A hiperactividade não pode ser diagnosticada em crianças em idade de pré-escolar mas os educadores podem alertar para qualquer sintoma e encaminhar as crianças e os pais para educadores de ensino especial (com competências para avaliar situações específicas) e/ou para o médico pediatra. No pré-escolar podem detectar-se sintomas de atenção deficiente mas é apenas na idade escolar, em que as crianças são levadas a cumprir tarefas que exigem maior atenção e requerem a dedicação da criança por mais tempo que se pode fazer o diagnóstico; é neste contexto, das tarefas longas e exigentes que se detectam desvios ao nível da atenção, da concentração. Existe uma confusão geral entre os educadores e os pais sobre o que podem ser sintomas de hiperactividade e a personalidade da criança: o diagnóstico é feito em função do que se quer da criança, de uma escala de avaliação precisa sobre as capacidades da criança em determinado nível de desenvolvimento; muitas vezes são os próprios pais que dizem: o meu filho não se concentra, ele é hiperactivo. Há hoje uma carga da sociedade sobre as crianças que as torna mais agitadas, mais irrequietas, que as estimula muito mais; crianças com necessidades afectivas particulares também tendem a chamar mais a atenção dos adultos, dos educadores, o que por vezes pode levar a que sejam precocemente e erradamente encaminhadas para o médico com sintomas de hiperactividade. As crianças hiperactivas são medicadas com estimulantes para aumentar o seu nível de concentração; mas deverá haver com certeza vários tipos de medicação na medida em que, imagina, existem vários tipos de "hiperactividades".

Entrevista O: Educador de infância há cerca de 11 anos, Viseu (Silgueiros). Entrevistadora: Já teve crianças hiperactivas?

Educador O: "Não, felizmente"

Entrevistadora: O que sabe sobre hiperactividade?

Educador O: "nunca tive necessidade de saber porque nunca tive nenhum caso. Falamos disso muito pela rama durante o curso. Agora não sei quase nada. Sempre que se desconfia de uma situação pede-se o apoio de alguém que seja da área. Pede-se um apoio mais específico".

Entrevista P: Professor do ensino básico há cerca de 12 anos, Viseu. 
Entrevistadora: Já teve crianças hiperactivas?

Professor P: "Sim".

Entrevistadora: O que sabe sobre hiperactividade?

Professor P: "Sei que são alterações no foro comportamental e não sei mais nada."

São poucos os profissionais que sabem realmente bem de que tipo de problema se trata, quais as características, e como lidar com a criança. Acho particularmente interessantes os que nada sabem e só quando estiverem perante um caso é que vão tentar saber o que é e pedir ajuda indicada. Porém agradeço a honestidade aos que corajosamente souberam ainda assim dizer que nada sabiam. A criança hiperactiva tem outro tipo de peculiaridades “... ela é apressada, impaciente, não toma tempo para pensar, para olhar e ouvir bem; não aguarda a sua vez para dar a resposta; é a primeira a responder, sendo a sua resposta frequentemente errada" (Rebelo, 1986: 205). Estas características deixam consternados muitos professores e educadores. E a avaliar por estas entrevistas, mesmo os que nunca tiveram experiência própria quando são questionados dizem mesmo: Não, felizmente nunca tive nenhum aluno hiperactivo. Os hiperactivos perturbam muito as salas de aula, desestabilizam a turma, atrasam os conteúdos programados porque interrompem bastante. Muitos destes entrevistados, disseram que os comportamentos mais repetitivos que os hiperactivos, que tinham tido como experiência, executavam era afiar o lápis, fazer muito barulho com as canetas e com as folhas. Outra situação muito engraçada é, deixarem cair a borracha de propósito para terem um pretexto de se levantarem. Um facto muito interessante que alguns destes professores me revelaram tem a ver com certas actividades que por vezes são executadas na escola e que de alguma forma prendem a atenção destas crianças. Quando assim é, gera-se outro problema. São incapazes de "mudar de disco" (Rebelo, 1986: 205). Isto é, não têm noção de quando parar. Isto só me faz crer que, são crianças com capacidade de concentração. Tanto que certas actividades são capazes de os cativar. Então, talvez se possa dar o caso de estas crianças necessitarem de uma maior estimulação em relação às outras. Talvez caiba a quem ensina/ educa crianças hiperactivas saber cativar-lhe a atenção. Deste ponto de vista, são crianças extremamente exigentes. Anseiam constantemente pela novidade. Outra questão pertinente está ainda relacionada com esta relação pais e escola, escola e pais. Penso que, cada vez mais será necessário que estes 
dois agentes se moldem e actuem de forma a beneficiar a criança. A ideia com que fiquei ao longo destes três anos de pesquisa é que há uma falha de ambas as partes. Julgo que nem a escola pode falhar com o apoio à criança nem os pais podem esperar que seja da competência da escola resolver a questão. "A cooperação e concertação entre todos os adultos que gravitam em torno da criança revelam-se essenciais, a vários níveis...estabelecer a coerência e manter as mesmas exigências, tanto na escola como em casa, é um princípio que fornece ao jovem o necessário enquadramento para o seu bom funcionamento" (Sauvé, 2006: 64-65).

\section{Agradecimentos:}

Agradeço ao Professor Luís Quintais.

\section{Referências bibliográficas}

Associação Americana de Psiquiatria 2002. Manual de diagnóstico e estatística dos distúrbios mentais. (DSM-IV-R). Lisboa, Associação Americana de Psiquiatria. Associação Americana de Psiquiatria 1996. Manual de diagnóstico e estatística dos distúrbios mentais. (DSM-IV). Lisboa, Associação Americana de Psiquiatria. Associação Americana de Psiquiatria 1986. Manual de diagnóstico e estatística dos distúrbios mentais.(DSM-III). Lisboa, Associação Americana de Psiquiatria. American Psychiatric Association 1987. Diagnostic and statistical manual of mental disorders. (DSM-III-R). Washington, DC, American Psychiatric Association. Augé, M.; Colleyn, J. P. 2005. A Antropologia. Lisboa, Edições 70.

Barkley, R. 1998. Attention-deficit hiperactivity disorder. A handbook for diagnosis and treatment. New York, Guilford Press.

Boavida, J.; Porfírio, H.; Nogueira, S.; Borges, L. 1998. A criança hiperactiva. Saúde Infantil, 20(3): 21-30.

Burgess, R. 1997. A pesquisa de terreno. Uma introdução. Oeiras, Celta Editora.

Brown. J. 1998. Understanding and applying medical anthropology. California, Mayfield Publishing Company.

Canguilhem, G. 1994. Le normal et le pathologique. Paris, Quadrige.

Duarte, S. 2002. Saberes de saúde e de doença. Porque vão as pessoas ao médico. Coimbra, Quarteto. 
Educação especial. [Online]. Lisboa, DGIDC. [Consultado em 29-08-2007]. Diponível em http://www.dgidc.min-edu.pt/especial/PDF/avaliacaoNEE.pdf.

Fontes, V. 1948. A psicossomática e a neuro-psiquiatria infantil. Arquivo de Anatomia e Antropologia, 25: 403-429.

Fonseca, A. 1998. Problemas de atenção e hiperactividade na criança e no adolescente: questões e perspectivas actuais. Psychologica, 19: 17-41.

Foucault, M. 1977. Vigiar e punir. História da violência nas prisões. Petrópolis, Vozes.

Fukuyama, F. 2002. O nosso futuro pós humano: consequências da revolução biotecnológica. Lisboa, Quetzal Editores.

Goldstein, J. 1987. Console and classify. The french psychiatric profession in the nineteenth century with a new afterword. Chicago, University of Chicago Press.

Good, B. 1994. Medicine, rationality, and experience. An anthropological perspective. Cambridge, Cambridge University Press.

Hahn, R.; Kleinman, A. 1983. Biomedical practice and anthropological theory: frameworks and directions. Anthropology, 12: 305-333.

Horgan, J. 1999. The undiscovered mind. How brain defies explanation. London, Phoenix Mass Market.

Kleinman, A. 1991. Rethinking psychiatry: from a cultural category to personal experience. New York, Free Press.

Kleinman, A. 1980. Patients and healers in the context of Culture. An exploration of the borderland between anthropology, medicine and psychiatry. Berkley, University of California Press.

Littlewood, R. 1996. Etnopsychiatry. In: Barnard Allen; Jonathan Spencer (eds.) Encyclopedia of Social and Cultural Anthropology. London, Routledge: 198-202.

Lopes, J. 2004. A Hiperactividade. Coimbra, Quarteto.

Quartilho, M. 2001. Cultura, medicina e psiquiatria. Do sintoma à experiência. Coimbra, Quarteto.

Quintais, L. 2000. As guerras coloniais portuguesas e a invenção da história. Lisboa, Imprensa de Ciências Sociais.

Quintais, L. 2002. O teatro da destruição e da verdade e a psiquiatria do século XIX. Revista de História das Ideias, 23: 365-387.

Rebelo, J. 1986. Para uma delimitação da noção de criança hiperactiva. Revista Portuguesa de Pedagogia, 20: 203-218.

Sanjek, R. 1996. Ethnography. In: Barnard Allen; Jonathan Spencer (eds.) Encyclopedia of Social and Cultural Anthropology. London, Routledge: 193-198. 
Sauvé, C. 2006. Domesticar a hiperactividade e o défice de atenção. Crescer e viver. Lisboa, Climepsi Editores.

Swaan, A. 1990. The management of normality: critical essays in health and welfare. New York, Routledge.

Toren, C. 1996. Chidhood. In: Barnard Allen; Jonathan Spencer (eds.) Encyclopedia of Social and Cultural Anthropology. London, Routledge: 92-94.

Young, A. 1995. The harmony of illusions. Inventing post- traumatic stress disorder. Princeton, Princeton University Press.

Artigo recebido a 25 de Fevereiro de 2010 e aceite a 19 de Abril de 2010. 